\title{
Cashew nut shells as source of chemicals for preparation of chalcogenide nanoparticles
}

\author{
E. B. Mubofu ${ }^{1, *}$, S. Mlowe ${ }^{1,2}$, N. Revaprasadu ${ }^{2}$ \\ ${ }^{1}$ Chemistry Department, University of Dar es Salaam, P.O. Box 35061, Dar es Salaam, Tanzania \\ ${ }^{2}$ Chemistry Department, University of Zululand, Private Bag X1001, KwaDlangezwa, 3886, South Africa \\ *ebmubofu@gmail.com, ebmubofu@udsm.ac.tz, sixb2809@gmail.com, RevaprasaduN@unizulu.ac.za
}

PACS 81.07.-b

DOI 10.17586/2220-8054-2016-7-4-724-727

\begin{abstract}
Cashew nut shell wastes produced in cashew nut processing factories cause environmental problems. Currently, these wastes are being converted to a variety of bio-based chemicals and functional materials. Cashew nut shells (CNS) produce cashew nut shell liquid (CNSL), a dark reddish brown viscous liquid ( $c$ a. $30-35$ wt. \%) which is extracted from the soft honeycomb of the CNS. CNSL offers multitude interesting possibilities for the synthesis of speciality chemicals, high value products and polymers due to their functionalities. Our recent research have demonstrated that CNSL constituents can be transformed into diverse functional chemicals. This contribution will report on how cashew nut shells (an agro waste from cashew nut processing factories) have been employed to produce anacardic acid capped chalcogenide nanoparticles.
\end{abstract}

Keywords: anacardic acid, cashew nut shell liquid, chalcogenide, nanoparticles.

Received: 5 February 2016

Revised: 7 May 2016

\section{Introduction}

Metal chalcogenides quantum dots (QDs) or semiconducting nanocrystals are interesting due to their highly refined chemistry, availability, and super tunable optical and electronic properties suitable for variety of applications in different fields, such as photovoltaics, light-emitting devices, environmental sciences and nanomedicine [1-7]. Recently, increasing concern about the environment has led researchers to focus on 'green chemistry', i.e. the utilization of nontoxic chemicals, environmentally benign solvents and renewable materials. The aforementioned are some of the key issues that merit important consideration in a green synthesis strategy. In order to reduce the environmental and health effects associated with nanoparticle synthesis, greener synthetic routes are being investigated $[8,9]$. Green chemistry aims at addressing ways to reduce environmental and health impacts of chemical production [10]. In the field of nanotechnology, green synthesis involves three key issues; "utilization of non-toxic chemicals, environmentally benign solvents, and renewable materials" [11].

Recently, researchers have begun using green renewable chemicals for the generation of inorganic nanostructures and materials. These chemicals have shown the capability to control architectures of materials at nanoscale level. Castor oil and ricinoleic acid [12], olive oil and oleic acid [13-16] and anacardic acid [17,18] are some of the green chemicals that have been used as capping agents to fabricate nanoparticles. In the present communication, we extend our earlier work using cashew nut shell liquid extracts for the synthesis of metal chalcogenides (Cadmium and lead sulfide, selenide and telluride) nanoparticles via a solution-based technique. Synthetic methods based on naturally occurring resources not only provide an alternative, friendly means of obtaining these metal chalcogenides nanoparticles, but also have a well-defined size and morphology. The use of cashew nut shell liquid and its isolate, anacardic acid (Fig. 1), in nanoparticle synthesis is associated with their chemical structures, easy availability, non-toxicity, low cost, non-food competition, high boiling point and high viscosity.<smiles>[R]c1cccc(O)c1C(=O)O</smiles>

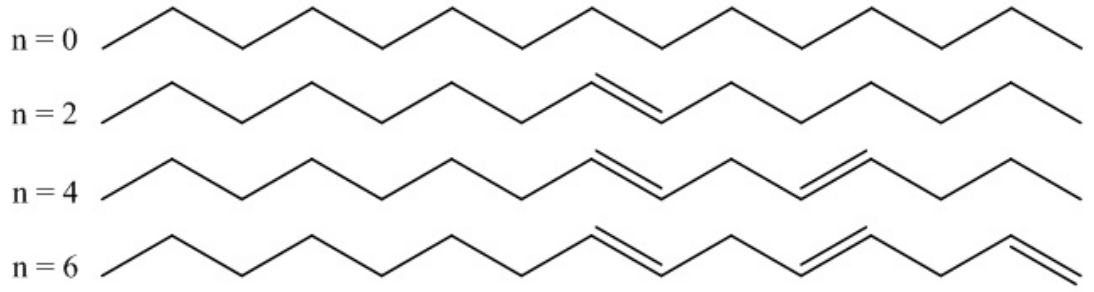

FIG. 1. Structure of Anacardic acids [19] 


\section{Experimental procedure}

The chemical reduction and thermolysis route has been employed in this work. The cashew nut shell liquid and its isolate, anacardic acid, were extracted using a procedure reported by Paramashivappa et al. [20] with slight modifications reported by Lucio et al. [21]. Other chemicals, characterizations and procedures are similar to our earlier publications $[17,18]$. The reaction scheme is shown in Fig. 2. The as-synthesized particles were characterized by TEM and HRTEM techniques.

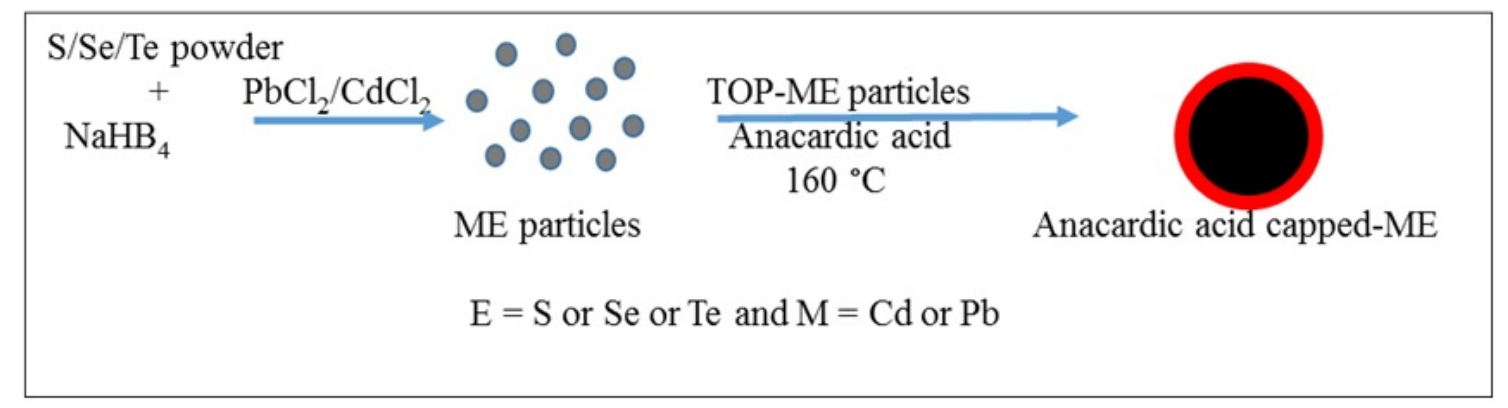

FIG. 2. Reaction scheme for the synthesis of anacardic acid-capped ME nanoparticles

\subsection{Results and discussion}

The morphology of the metal chalcogenide nanoparticles was studied by transmission electron microscopy (TEM). A typical TEM micrograph of the cadmium chalcogenide nanoparticles is given in Fig. 3. Fig. 3(a) shows anisotropic shaped anacardic acid-capped CdS nanoparticles, synthesized at $160{ }^{\circ} \mathrm{C}$ with average width of $11.8 \pm 2.4 \mathrm{~nm}$ and length $32.6 \pm 4.2 \mathrm{~nm}$. CdSe (Fig. 3b) displayed uniform rod-shaped nanocrystals with a narrow size distribution on the TEM grid. A similar trend was observed for CdTe nanoparticles, showing rod shaped particles with an average width of $16.3 \pm 3.0 \mathrm{~nm}$ and length $48.4 \pm 4.5 \mathrm{~nm}$ (Fig. 3(c)). There is almost an equal inter-particle distance of approximately $3 \mathrm{~nm}$ for the CdSe and CdTe particles as observed from the TEM images.

The TEM image of the as-synthesised anacardic acid capped PbS (Fig. 4(a)) consists of small undefined spherical like particles with an average size of $9.8 \pm 1.8 \mathrm{~nm}$. PbSe nanocrystals revealed the formation of small triangle-shaped particles with an average size of $12.6 \pm 3.1 \mathrm{~nm}$ (Fig. 4(b)). The presence of interspersed particles supports the fact that the formation of nanocrystals may be due to the influence of anacardic acid. While for PbTe nanoparticles (Fig. 4(c)), rod shaped and some cubic shaped particles, typical for PbTe [22] were formed. Rods of width $11.9 \mathrm{~nm}$ and length $37.8 \mathrm{~nm}$ and cubes of $20.9 \mathrm{~nm}$ were estimated.

\section{Conclusion}

Cadmium and lead chalcogenide (ME where $\mathrm{M}=$ cadmium or lead and $\mathrm{E}=\mathrm{S}$, Se or Te) nanoparticles have been successfully synthesized using anacardic acid as a coordinating solvent. The TEM studies reveal a mosaic-like pattern for all samples. Furthermore, monodispersed spherical to cubic shaped $\mathrm{PbE}$ nanoparticles were obtained. The results reveal that anacardic acid could be an effective and potential capping agent in the synthesis of metal chalcogenide nanoparticles. The method utilized an inexpensive and non-toxic naturallyoccurring acid as a capping agent which proved to be a good choice for high quality, monodispersed nanoparticles. 

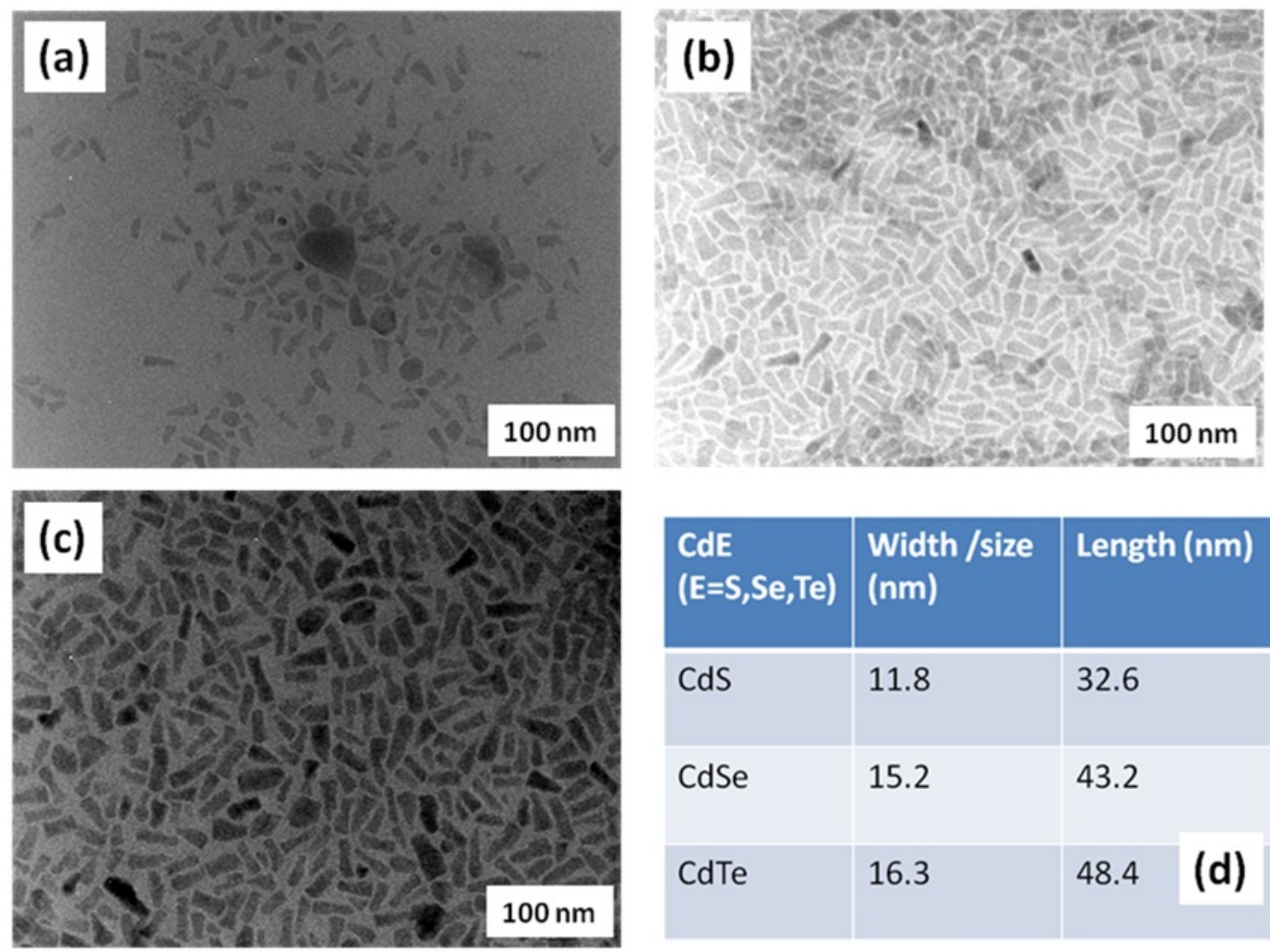

\begin{tabular}{|l|l|l|l|}
\hline $\begin{array}{l}\text { CdE } \\
(\mathrm{E}=\mathrm{S}, \mathrm{Se}, \mathrm{Te})\end{array}$ & $\begin{array}{l}\text { Width /size } \\
(\mathrm{nm})\end{array}$ & Length $(\mathrm{nm})$ \\
\hline $\mathrm{CdS}$ & 11.8 & 32.6 \\
\hline $\mathrm{CdSe}$ & 15.2 & 43.2 & \\
\hline CdTe & 16.3 & 48.4 & (d) \\
\hline
\end{tabular}

FIG. 3. TEM images of anacardic acid capped CdS (a), CdSe (b) and CdTe (c), and table showing their sizes (d) synthesized at $160{ }^{\circ} \mathrm{C}$
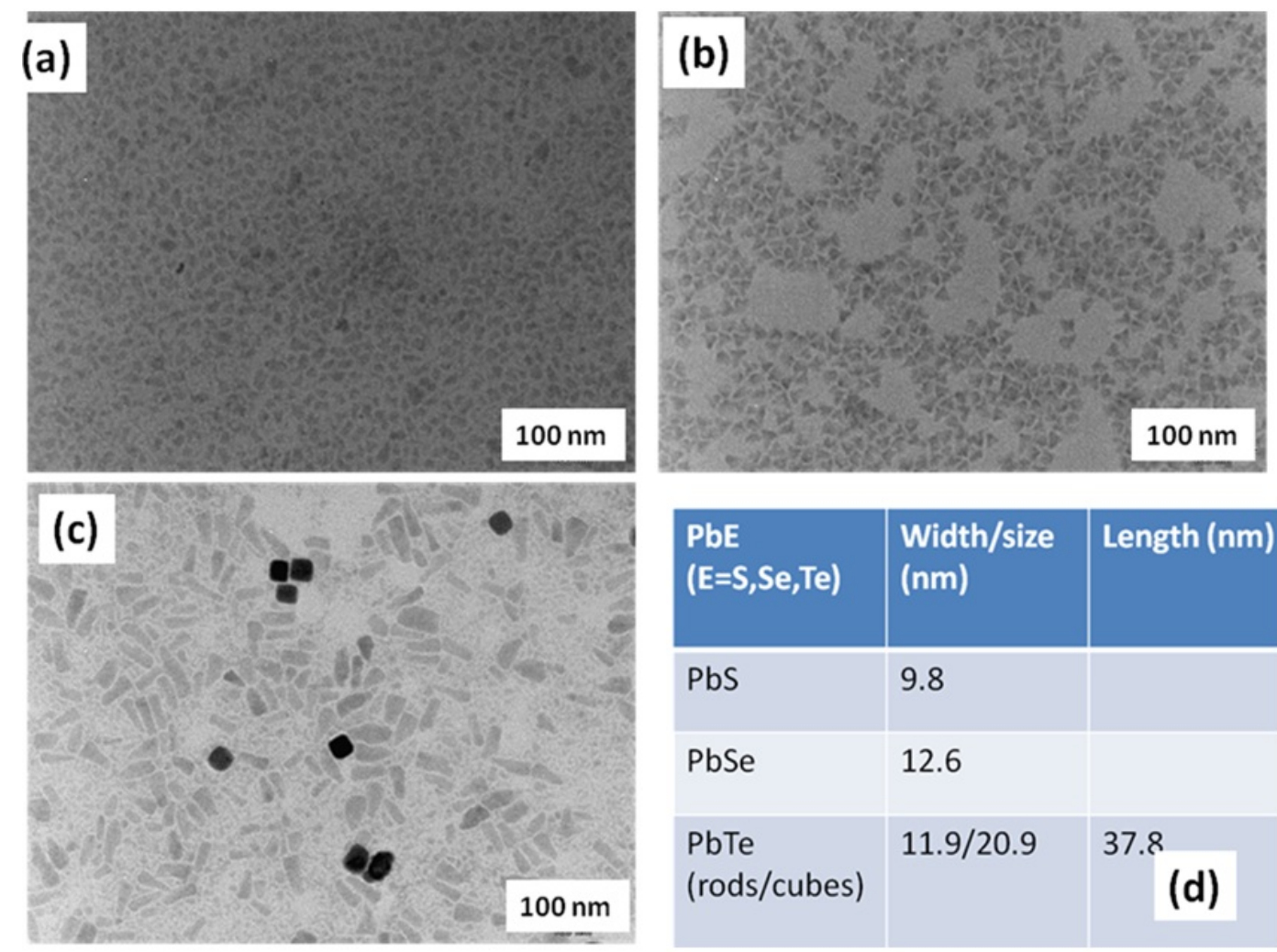

\begin{tabular}{|l|l|l|}
\hline $\begin{array}{l}\mathrm{PbE} \\
(\mathrm{E}=\mathrm{S}, \mathrm{Se}, \mathrm{Te})\end{array}$ & $\begin{array}{l}\text { Width/size } \\
(\mathrm{nm})\end{array}$ & Length $(\mathrm{nm})$ \\
\hline $\mathrm{PbS}$ & 9.8 & \\
\hline $\mathrm{PbSe}$ & 12.6 & 37.8 \\
\hline $\begin{array}{l}\mathrm{PbTe} \\
\text { (rods/cubes) }\end{array}$ & $11.9 / 20.9$ & (d) \\
\hline
\end{tabular}

FIG. 4. TEM images of anacardic acid capped $\mathrm{PbS}(\mathrm{a}), \mathrm{PbSe}(\mathrm{b})$ and $\mathrm{PbTe}(\mathrm{c})$, and table showing their sizes (d) synthesized at $160{ }^{\circ} \mathrm{C}$ 


\section{References}

[1] Fan F-J., Wu L., Yu S-H. Energetic I-III-VI 2 and $\mathrm{I}_{2}-\mathrm{II}-\mathrm{IV}-\mathrm{VI}_{4}$ nanocrystals: synthesis, photovoltaic and thermoelectric applications. Energy Environ. Sci., 2014, 7, P. 190-208.

[2] Lewis D.J., Kevin P., Bakr O., Muryn C.A., Malik M.A. and O’Brien P. Routes to tin chalcogenide materials as thin films or nanoparticles: a potentially important class of semiconductor for sustainable solar energy conversion. Inorg. Chem. Front., 2014, 1, P. 577-598.

[3] Min Y., Moon G.D., Kim C-E., Lee J-H., Yang H., Soon A., Jeong U. Solution-based synthesis of anisotropic metal chalcogenide nanocrystals and their applications. J. Mater. Chem. C, 2014, 2, P. 6222-6248.

[4] Santra P.K., Kamat P.V. Tandem-Layered Quantum Dot Solar Cells: Tuning the Photovoltaic Response with Luminescent Ternary Cadmium Chalcogenides. J. Am. Chem. Soc., 2013, 135(2), P. 877-885.

[5] Pan Z., Mora-Seró I., Shen Q., Zhang H., Li Y., Zhao K., Wang J., Zhong X., Bisquert J. High-Efficiency “Green” Quantum Dot Solar Cells. J. Am. Chem. Soc., 2014, 136(25), P. 9203-9210.

[6] Kaewsaneha C., Tangboriboonrat P., Polpanich D., Eissa M., Elaissari A. Janus Colloidal Particles: Preparation, Properties, and Biomedical Applications. ACS Appl. Mater. Interfaces, 2013, 5(6), P. 1857-1869.

[7] Akhtar J., Malik M.A., O’Brien P., Wijayantha K.G.U., Dharmadasa R., Hardman S.J.O., Graham D.M., Spencer B.F., Stubbs S.K., Flavell W.R., Binks D.J., Sirotti F., El Kazzi M., Silly M. A greener route to photoelectrochemically active PbS nanoparticles. J. Mater. Chem., 2010, 20, P. 2336-2344.

[8] Da Silva E.C., Da Silva M.G., Meneghetti S.M., Machado G., Alencar M.A., Hickmann J.M., Meneghetti M.R. Synthesis of Colloids Based on Gold Nanoparticles Dispersed in Castor Oil. J Nanopart Res., 2008, 10, P. 201-208.

[9] Devendran P., Alagesan T., Ravindran T.R., Pandian K. Synthesis of Spherical CdS Quantum Dots Using Cadmium Diethyldithiocarbamate as Single Source Precursor in Olive Oil Medium. Current Nanoscience., 2014, 10, P. 302-307.

[10] Paul A., Warner T., John C. Green Chemistry: Theory and Practice. Oxford [England], New York: Oxford University Press, 1998.

[11] Raveendran P., Fu J., Wallen S.L. Completely "Green" Synthesis and Stabilization of Metal Nanoparticles. J. Am. Chem. Soc., 2003, 125, P. 13940-13941.

[12] Kyobe J.W., Mubofu E.B., Makame Y.M.M., Mlowe S., Revaprasadu N. CdSe quantum dots capped with naturally occurring biobased oils. New J. Chem., 2015, DOI: 10.1039/C5NJ01460C.

[13] Nyamen L.D., Revaprasadu N., Ndifon P.T. Low temperature synthesis of PbS and CdS nanoparticles in olive oil. Mater. Sci. Semicond. Process., 27, P. 191-196, 2014.

[14] Devendran P., Alagesan T., Ravindran T.R., Pandian K. Synthesis of spherical CdS quantum dots using cadmium diethyldithiocarbamate as single source precursor in olive oil medium. Curr. Nanosci., 2014, 10, P. 302.

[15] Sapra S., Rogach A.L., Feldmann J. Phosphine-free synthesis of monodisperse CdSe nanocrystals in olive oil. J. Mater. Chem., 2006, 16, P. 3391-3395.

[16] Chen J., Song J.L., Sun X.W., Deng W.Q., Jiang C.Y., Lei W., Huang J.H., Liu R.S. An oleic acid-capped CdSe quantum-dot sensitized solar cell. Appl. Phys. Lett., 2009, 94, P. 153115. doi: 10.1063/1.3117221.

[17] Mlowe S., Pullabhotla V.S.R., Mubofu E.B., Ngassapa F.N., Revaprasadu N. Low temperature synthesis of anacardic acid capped cadmium chalcogenide nanoparticles. Int. Nano. Lett., 2014, 4, P. 106.

[18] Mlowe S., Pullabhotla V.S.R., Mubofu E.B., Ngassapa F.N., Nejo A.A., O’Brien P., Revaprasadu N. Lead chalcogenides stabilized by anacardic acid. Mater. Sci. Semicond. Process., 2013, 16, P. 263-268.

[19] Tyman J.H.P. Long-chain phenols. V. Gas chromatographic analysis of cashew nut-shell liquid. (Anacardium occidentale). J. Chromatog, 1975, 111, P. 285-292.

[20] Paramashivappa R., Kumar P.P., Vithayathil P.J., Rao A.S. Novel method for isolation of major phenolic constituents from cashew (Anacardium occidentale L) Nut Shell Liquid. J. Agric. Food Chem., 2001, 49, P. 2548-2551.

[21] Lucio P.L.L., Santos C.O., Romeiro L.A.S., Costa A.M., Ferreira J.R.O., Cavalcanti B.C., Moraes O.M., Costa-Lotufo L.V., Pessoa C., Santos M.L. Synthesis and cytotoxicity screening of substituted isobenzofuranones designed from Anacardic acids. Eur. J. Med. Chem., 2010, 45, P. 3480-3489.

[22] Mokari T., Zhang M., Yang P. Shape, size, and assembly control of PbTe nanocrystals. J. Am. Chem. Soc., 2007, 129, P. 9864-9865. 